\title{
Adsorption performance of packed bed column for nitrate removal using PAN-oxime-nano $\mathrm{Fe}_{2} \mathrm{O}_{3}$
}

\author{
Mahsa Jahangiri-rad ${ }^{1 *}$, Arsalan Jamshidi ${ }^{2}$, Mohammad Rafiee $^{3}$ and Ramin Nabizadeh ${ }^{4}$
}

\begin{abstract}
A continuous fixed bed study was carried out by using PAN-oxime-nano $\mathrm{Fe}_{2} \mathrm{O}_{3}$ as a sorbent for the removal of nitrate from aqueous solution. The effect of factors, such as flow rate $(2,5$ and $7 \mathrm{~mL} / \mathrm{min})$ and bed depth $(5,10$ and $15 \mathrm{~cm}$ ) were studied. Data confirmed that the breakthrough curves were dependent on flow rate and bed depth. The adsoption capacities observed in diffent conditions of flow rates $(2,5$ and $7 \mathrm{~mL} / \mathrm{min})$ were $11.65,24.38$ and 25.89, respectively. Thomas model was applied to experimental data to predict the breakthrough curves using linear regression and to determine the characteristic parameters of the packed bed column. Bed depth/service time analysis (BDST) model was used to investigate the effect of bed depth on breakthrough curves. The results showed that Thomas model was suitable for the normal description of breakthrough curve at the experimental condition. The data were in good agreement with BDST model with $R^{2}>0.98$. Statistical analyses were performed on fluoride removal obtained from different flow rates using SPSS16 software by applying Kruskal- Wallis test. These findings suggested that PAN-oxime-nano $\mathrm{Fe}_{2} \mathrm{O}_{3}$ in the column structure presents a great potential in removal of nitrate from aqueous solutions.
\end{abstract}

Keywords: PAN-oxime-nano $\mathrm{Fe}_{2} \mathrm{O}_{3}$, Niatrate, Sorption, Packed bed column, Breakthrough curve

\section{Introduction}

The principal sources of nitrogen are from nitrogeneous compounds produced by plant and animals or the mining of sodium nitrate for use in fertilizers, and the atmosphere. The most oxidized form of nitrogen is nitrate $\left(\mathrm{NO}_{3}^{-}\right)[1,2]$. World wide, the average intake of nitrate is about 75 to $100 \mathrm{mg} / \mathrm{d}$, of which approximately 80 to 90 percent comes from vegetables. people on a vegetarian diet may consume as much as $250 \mathrm{mg} / \mathrm{d}$ of nitrate. Accordingly, drinking water accounts for only 5 to 10 percent of nitrates consumed [3]. However, if the nitrate levels in the water are five times the MCL (10 $\mathrm{mg} / \mathrm{L})$, water may supply a person about half the daily diet requirements ${ }^{3}$. Nitrate is of primary concern for infants younger than 6 months of age. Infants are very susceptible to methemoglobinemia, a condition known as "blue baby syndrome." High nitrate levels that are reduced in the stomach and/or the saliva of an infant to nitrite cause blue baby syndrome. Nitrite in the blood combines with hemoglobin to form

\footnotetext{
* Correspondence: Mahsajahangiri_64@yahoo.com

'Department of Environmental Health Engineering, Islamic Azad University,

Tehran Medical Sciences Branch, Tehran, Iran

Full list of author information is available at the end of the article
}

methemoglobin, which reduces the capability of the blood to transport oxygen throughout the body. This results in the skin of a baby turning blue and can be fatal [4]. The present MCL in the United States is $10 \mathrm{mg} / \mathrm{L}$ as nitrate and Canada has established a maximum acceptable concentration (MAC) of $10 \mathrm{mg} \mathrm{NO}(\mathrm{N} / \mathrm{L})$. Due to the fact that nitrate is a stable, highly soluble ion, it is difficult to remove by conventional processes [4]. Present technologies for nitrate removal from water supplies include chemical and biological denitrification [5], reverse osmosis [6], electrodialysis [7], ion exchange [8] and adsoprtion [9]. The process of adsorption of the material through of a fluid mixture flowing in to a packed column has gained great interest in recent years. There is a need to carry out the column studies to assess the required contact time for the adsorbate to achieve equilibrium as the results obtained from the batch studies for the contaminants adsorption studies may not be directly applied for field application in the treatment of polluted water [10]. In the present study, PAN-oxime-nano $\mathrm{Fe}_{2} \mathrm{O}_{3}$ were used for nitrate removal. Continuous adsorption experiments were conducted to understand and quantify the effect of influencing parameters such as, initial floe rates and bed 


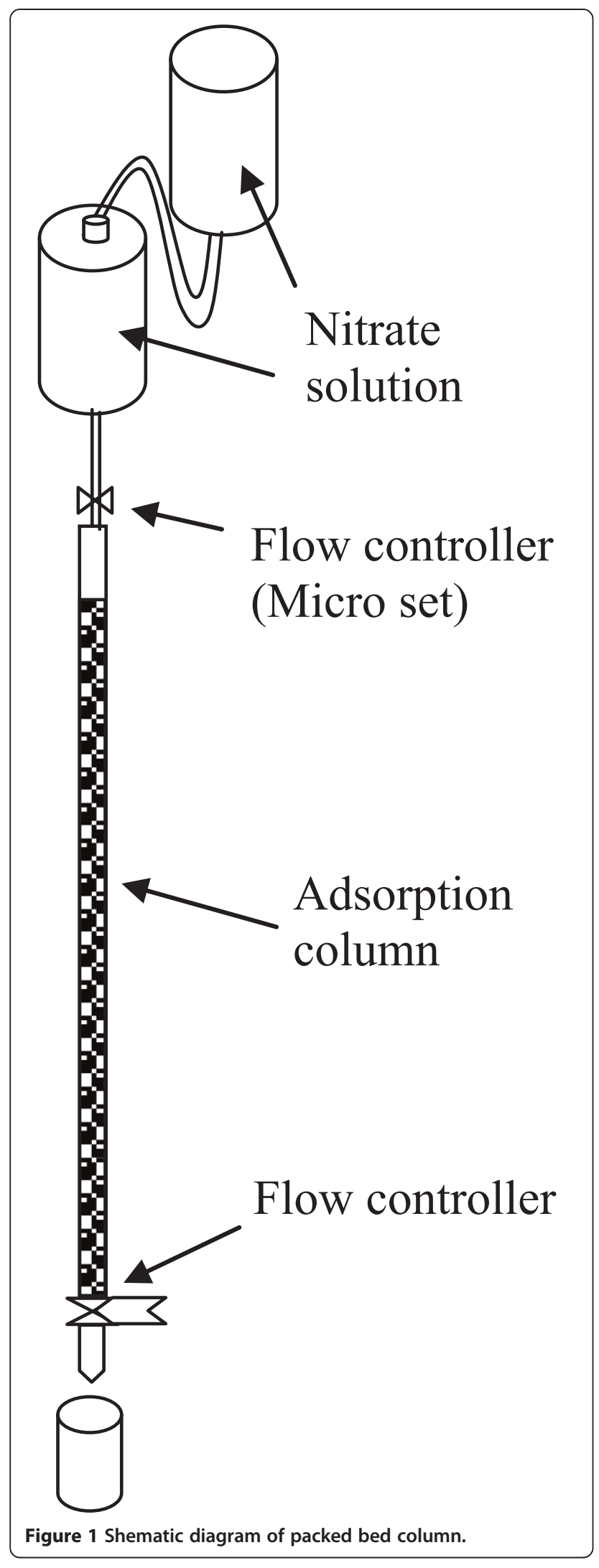

heights on breakthrough curve. BDST model, which offers a simple approach and rapid prediction of adsorber performance, is applied for modelling adsorption of nitrate in PAN-oxime-nano $\mathrm{Fe}_{2} \mathrm{O}_{3}$ column.

\section{Material and methods}

Preparation and characterization of PAN-oxime-nano $\mathrm{Fe}_{2} \mathrm{O}_{3}$ Hydroxilamine hydrochloride (16 g), sodium carbonate $(12 \mathrm{~g})$, and $0.4 \mathrm{~g}$ of PAN powder were added to a $250 \mathrm{~mL}$ bottle to which $100 \mathrm{~mL}$ of deionized water was added and shaken. The reaction was carried out at $70^{\circ} \mathrm{C}$ for $120 \mathrm{~min}$. After reaction, the resultant was filtered and let to dry. $\mathrm{Fe}_{2} \mathrm{O}_{3}$ was coated on PAN functionalized by adding $0.2 \mathrm{~g}$ of selected $\mathrm{Fe}_{2} \mathrm{O}_{3}$ and $100 \mathrm{~mL}$ deionized water in a sealed bottle. The solution was shaken at $70^{\circ} \mathrm{C}$ for $120 \mathrm{~min}$. The resultant was filtered and dried in a vacuum oven at $60^{\circ} \mathrm{C}$. PAN functionalized- $\mathrm{Fe}_{2} \mathrm{O}_{3}$ was used as an adsorbent. The characteristics of PAN-oxime-nano $\mathrm{Fe}_{2} \mathrm{O}_{3}$ was studied by XRD, FTIR and SEM in our earlier study [11].

\section{Experimental procedure}

Countinous flow adsorption experiment was conducted in polyethylene columns of $0,5 \mathrm{~cm}$ diameter. known quantity of the prepared was packed in the column to yield the desired height of the adsorbent equivalent to $10 \mathrm{~g}$ of PAN-oxime-nano $\mathrm{Fe}_{2} \mathrm{O}_{3}$.At the top of the column the influent nitrate solution $(50 \mathrm{mg} / \mathrm{l})$ was entered the packed column $(10,15$ and $20 \mathrm{~cm})$ at flow rates of 2,5 and $7 \mathrm{~mL} / \mathrm{min}$, using a microset serium. In order to keep the height of nitrate consistent in microset reserviour another feed preservor was installed (Figure 1). The first tank delivers the solution to the second tank at a constant flow rate. The second tank (Micro set) is equipped with a flow controller to help maintain a constant flow rate of the solution being delivered to the column. Smples were collected from the exit of the column at regular time intervals. The samples' supernatant were separated by centrifugation at $4000 \mathrm{rpm}$ for $10 \mathrm{~min}$. The residual concentration in the supernatants were determined. The nitrate concentration in treated sample were determined by UV-vis Spectrophotometer. The saturation capacity for the PAN-oxime-nano $\mathrm{Fe}_{2} \mathrm{O}_{3}$ was calculated from the following equation:

$$
q_{e}=\int_{0}^{V_{e}}\left(C_{0}-C_{\mathrm{e}}\right) \mathrm{dv} / \mathrm{m}
$$

Table 1 Descriptive statistical analysis of various flow rates on fluoride removal at time of $9 \mathrm{~h}$

\begin{tabular}{llllll}
\hline & N & Mean & Std. deviation & Minimum & Maximum \\
\hline Removal & 15 & 85.3333 & 8.72326 & 73.00 & 95.00 \\
Flow & 15 & 4.6667 & 2.12692 & 2.00 & 7.00 \\
\hline
\end{tabular}


Table 2 Results of Kruskal Wallis test statistics

\begin{tabular}{ll}
\hline & Removal \\
\hline Chi-Square & 12.844 \\
df & 2 \\
Asymp. Sig. & .002 \\
\hline
\end{tabular}

Where $\mathrm{q}_{\mathrm{e}}$ is the nitrate adsorbed $(\mathrm{mg} / \mathrm{g}), \mathrm{C}_{0}$ is the influent nitrate concentration $(\mathrm{mg} / \mathrm{L}) \mathrm{C}_{\mathrm{e}}$ is effluent nitrate concentration $(\mathrm{mg} / \mathrm{L}), \mathrm{V}_{\mathrm{e}}$ is the volume of solution required to reach the exhaustion point $(\mathrm{L})$ and $\mathrm{m}$ is the mass of adsorbent (g).

\section{Modeling of column operation}

Full-scale column operation was designed according to the data collected in laboratory level. Many mathematical models have been used for the evaluation of efficiency and applicability of the column models for full scale operations. To design a column sorption process it was necessary to predict the breakthrough curve or concentration time profile and sorption capacity of the sorbent for the selected sorbate. Many models have been developed to predict the sorption breakthrough behaviour with high degree of accuracy. In this study the Thomas model was used to evaluate the behaviour of the selected adsorbentadsorbate system.

\section{Results and discussion}

\section{Adsorption capacity of the column}

Adsorption capacity of PAN-oxime-nano $\mathrm{Fe}_{2} \mathrm{O}_{3}$ was determined with thomas models. Different volumes of samples containing nitrate $(50 \mathrm{mg} / \mathrm{L})$ was passed through the column. The sampling was proceeding until nitrate concentration in outlet reach to nitrate concentration in feed. The adsoption capacities obtained for diffent flow rates $(2,5$ and $7 \mathrm{~mL} / \mathrm{min})$ were $11.65,24.38$ and 25.89 ,

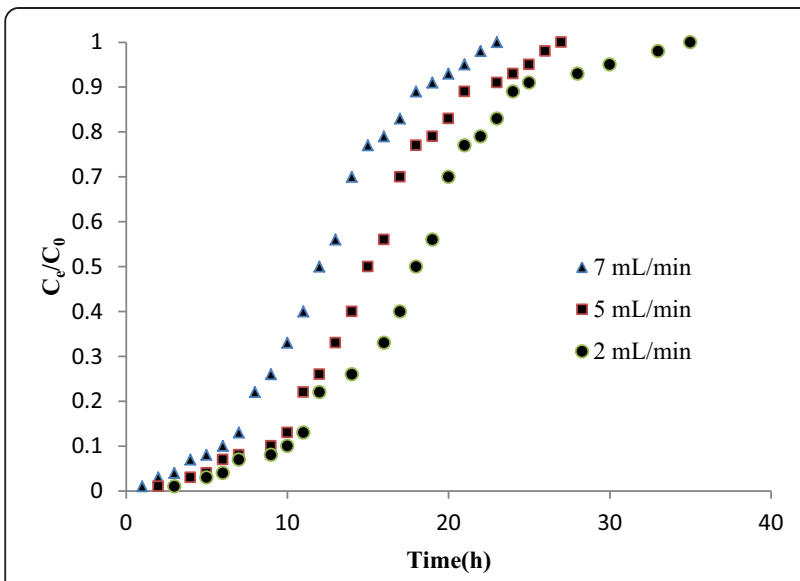

Figure 2 Effect of flow rate on breakthrough curve for nitrate adsorption (bed height $15 \mathrm{~cm}$ ).

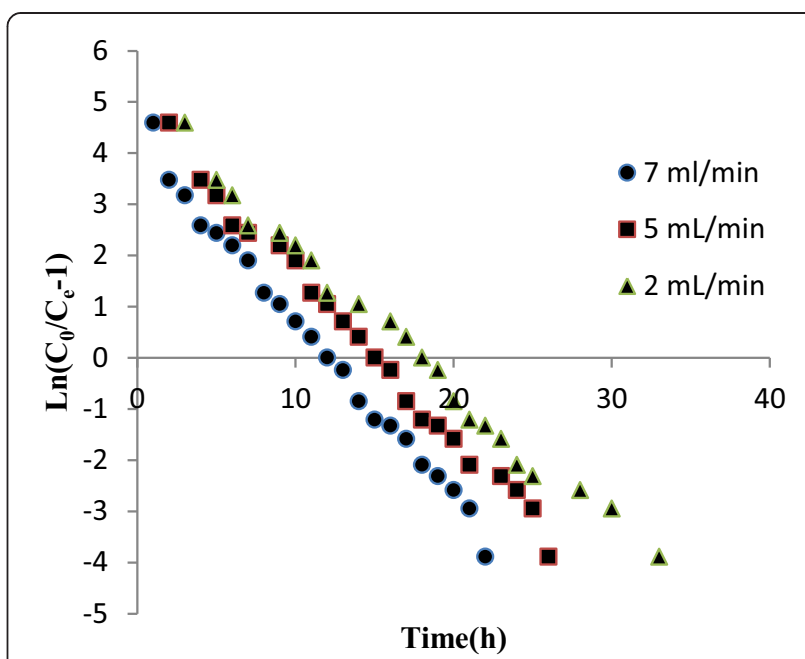

Figure 3 Thomas kinetic plots for the adsorption of adsorption: Effect of flow rate (bed height $15 \mathrm{~cm}$ ).

respectively (Tables 1 and 2). The maximum adsorption capacity $\left(\mathrm{q}_{0}\right)$ increased with increase in flow rate.

\section{Effect of flow rate}

The adsorption columns were operated with different flow rates $(2,5$ and $7 \mathrm{~mL} / \mathrm{min})$ and bed height $(10,15$ and $20 \mathrm{~cm}$ ) untill no further nitrate removal was observed. The breakthrough curve for the column was determined by plotting $\mathrm{C}_{\mathrm{e}} / \mathrm{C}_{0}$ against time (Figure 2). The column performed well at lowest flow rate $(2 \mathrm{~mL} / \mathrm{min})$. As the flow rates and times increased, Earlier breakthrough was observed. The column breakthrough time $\left(\mathrm{C}_{\mathrm{e}} / \mathrm{C}_{0}=0.05\right)$ was reduced from 9 to $4 \mathrm{~h}$, as the flow rates increase from 2 to $7 \mathrm{~mL} / \mathrm{min}$. This can be due to the two phenomenon: a) a decrease in the residence time which inhibited nitrate contaction to the adsorbent and b) nitrate does not have enough time to diffuse in to the pores of adsorbent and it

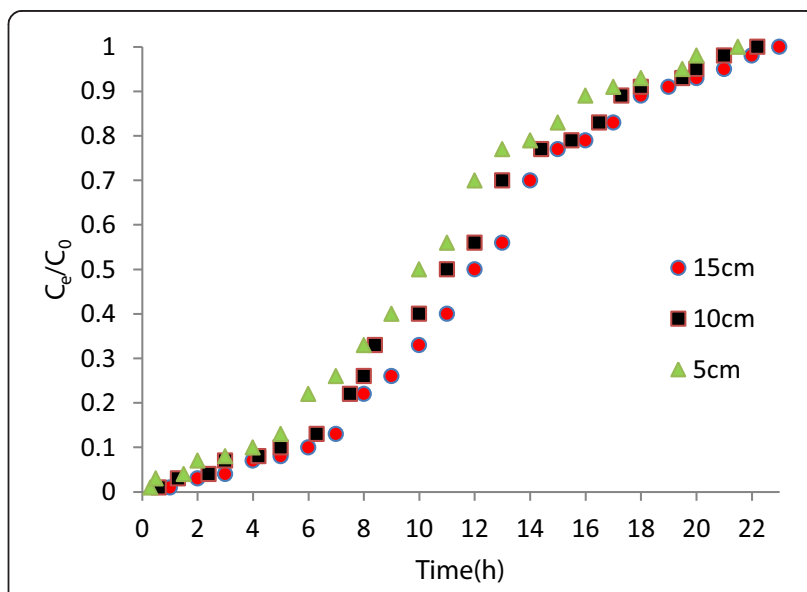

Figure 4 Effect of bed height on breakthrough curve for nitrate adsorption on. 
Table 3 The Thomas and BDST model parametres for adsorption of nitrate on PAN-oxime-nano $\mathrm{Fe}_{2} \mathrm{O}_{3}$

\begin{tabular}{cccc}
\hline \multicolumn{4}{l}{ Thomas model parameters } \\
\hline Flow rate $(\mathbf{m L} / \mathbf{m i n})$ & $\mathbf{q}_{\mathbf{0}}(\mathbf{m g} / \mathbf{g})$ & $\mathbf{K}_{\mathrm{th}}(\mathbf{L} / \mathbf{m g ~ h})$ & $\mathbf{R}^{\mathbf{2}}$ \\
\hline 2 & 11.65 & 0.0054 & 0.987 \\
5 & 24.38 & 0.0064 & 0.991 \\
7 & 25.89 & 0.0071 & 0.991 \\
\hline BDST $\mathbf{m o d e l}$ parameters & & & \\
\hline $\mathbf{N}(\mathbf{m g} / \mathbf{L})$ & $\mathbf{K}_{\mathbf{a}}(\mathbf{L} / \mathbf{m g ~ h})$ & \multicolumn{2}{c}{$\mathbf{R}^{\mathbf{2}}$} \\
\hline 1433 & 0.0112 & \multicolumn{2}{c}{0.956} \\
\hline
\end{tabular}

exited the column without being adsorbed. So at high flow rate the adsorbate solution leavesthe column before equilibrium occures. Similar results was observed in the cases of the copper and nickel rimoval [12]. Thomas model kinetic models was used to analyze the column performance. Thomas model has been used by many researchers to study packed bed adsorption kinetics [13]. The linearized form of the Thomas model is described by equation (1):

$$
\operatorname{Ln}\left(\mathrm{C}_{0} / \mathrm{C}_{\mathrm{e}}-1\right)=\left(\mathrm{K}_{\mathrm{th}} \mathrm{q}_{0} \mathrm{M} / \mathrm{Q}\right)-\left(\mathrm{k}_{\mathrm{th}} \mathrm{C}_{0} \mathrm{t}\right)
$$

Where $C_{e}, C_{0}=$ the effluent and inlet solute concentrations $(\mathrm{mg} / \mathrm{l})$ at any time $(\mathrm{t})$, qo $=$ the maximum adsorption capacity $(\mathrm{mg} / \mathrm{g}), \mathrm{M}=$ the total mass of the adsorbent $(\mathrm{g})$, $\mathrm{Q}=$ volumetric flow rate $(\mathrm{mL} / \mathrm{h})$ and $\mathrm{K}_{\mathrm{th}}=$ the Thomas rate constant $(\mathrm{mL} / \mathrm{mg} \mathrm{h})$. The kinetic coefficient, Kth and the adsorption capacity of the bed, qo were determined from the plot of $\operatorname{Ln}\left[\left(C_{0} / C_{e}\right)-1\right]$ against $t$ at a given flow rate (Figure 3). The model parameters are given in Tables 1 and 2 . Thomas rate constant, $K_{\text {th }}$ is dependent on flow rate. The adsoption capacities obtained for diffent flow rates $(2,5$ and $7 \mathrm{~mL} / \mathrm{min})$ were $11.65,24.38$ and 25.89 , respectively (Tables 1 and 2). The maximum adsorption capacity $\mathrm{q}_{0}$ increased with increase in flow rate which indicates that the mass transport resistance decreases.
The values of $K_{\text {th }}$ obtained in this research was similar to the ones obtained by other researchers $[14,15]$. The Thomas model fitted the experimental data well, with correlation coefficient greater than 0.98 , which indicates that the external and internal diffusions are not the rate limiting step. The results obtained from Statistical analysis on fluoride removal in different flow rates is depicted in Tables 1 and 2 . By the $P$ value calculated $(<0.05)$ it would be concluded that there is a difference among various flow rate tested. With 2 degrees of freedom, a value of Chi-Square as large as 12.84 is likely to occur by chance only 2 times in a thousand (it has a $p$ of 0.002).

\section{Effect of bed height}

In order to study the effect of bed height on nitrate removal, breakthrough curves for the adsorption of nitrate onto PAN-oxime-nano $\mathrm{Fe}_{2} \mathrm{O}_{3}$ at various bed heights, at the inlet concentration of $50 \mathrm{mg} / \mathrm{L}$ and flow rate of $2 \mathrm{~mL} / \mathrm{min}$ were obtained (Figure 4 ). The results indicated that the nitrate removal was increased with increase in bed height, due to the availability of more number of sorption sites. At lower bed depth, nitrate ions dont have enough time to adsorbed on adsorbent and a reduction in breakthrough time observed (from 3 to $1 \mathrm{~h}$ ). It was also observed that the maximum nitrate removal occurs at the initial stage of the experiments. After some time of operation the nitrate removal decreases and reaches to zerowhich might be due to nonavailability of sorbent site for the sorption to occur. Another important criteria "breakthrough service time" (BDST) model is used to evaluate the capacity of the bed at various percentage breakthrough values. This model assumes that the adsorption rate is proportional to both the residual capacity of adsorbent and the concentration of the adsorbing solute [16]. This model neglects both the external and internal mass transfer resistances. It is simple, rapid and applicable to predict the effect of

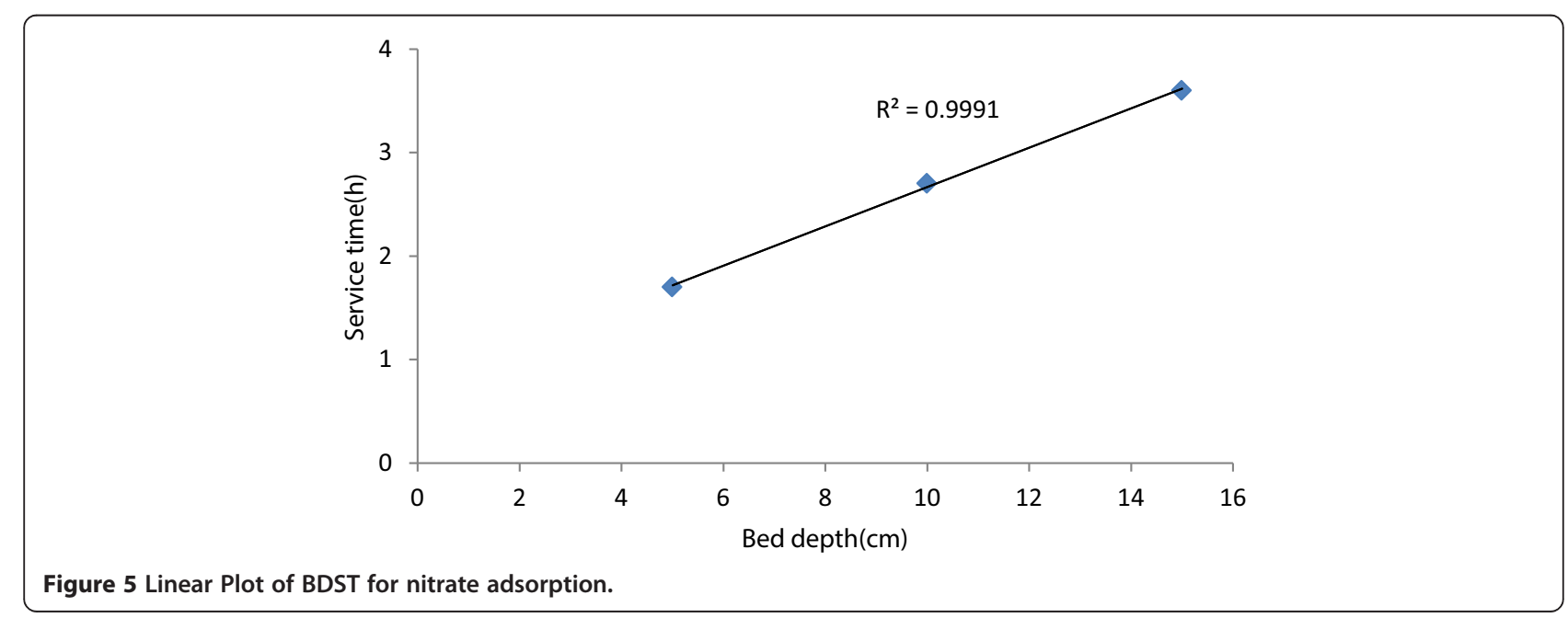


different inlet concentrations and bed depth and flow rates on the fixed bed performance. However its validity is limited to a certain range of conditions, for example to a specific range of breakthrough [17]. The BDST model assumes that the service time, ts, for a determined breakthrough concentration, $\mathrm{v}$, and the height of the bed, $\mathrm{Z}$, are correlated with the process parameters such as maximum adsorption capacity, and rate constant of adsorption in BDST model. The BDST model constants are helpful in determining the full scale process for othe flow rates and adsorbate concentrations without designing new experiments. The BDST equation calculated as follows [18]:

$$
t=\frac{N_{o} Z}{C_{o} v}-\frac{1}{K_{a} C_{o}} \ln \left(\frac{C_{o}}{C}-1\right)
$$

where $C$ is the breakthrough dye concentration $(\mathrm{mg} / \mathrm{L})$, $\mathrm{N}_{0}$ is the sorption capacity of bed $(\mathrm{mg} / \mathrm{L}), \mathrm{v}$ is the the linear velocity $(\mathrm{cm} / \mathrm{min})$ and $K_{a}$ is the rate constant ( $\mathrm{L} / \mathrm{mg} \mathrm{zmin})$. The values of BDST parameters are presented in Table. 3. The calculated adsorption capacity $\left(\mathrm{N}_{0}\right)$ and the rate constant $\left(\mathrm{K}_{\mathrm{a}}\right)$ are $1433 \mathrm{mg} / \mathrm{L}$ and $0.0112 \mathrm{~L} / \mathrm{mg} \mathrm{min}$, respectively. The value of $\mathrm{K}_{\mathrm{a}}$ shows the rate of transfer from the fluid phase to the solid phase. When $K_{a}$ is large even a short bed will avoid breakthrough but as $\mathrm{K}_{\mathrm{a}}$ decreases a deeper bed is required to avoid breakthrough. The advantage of the BDST model is that any experimental test can be reliably scaled up to other flow rates without further experimental runs. The column service time was calculated as the time when normalized concentration was reached. The plot of service time versus bed depth (Figure 5$)$ is linear $\left(R^{2}=0.999\right)$ indicating the validity of BDST model.

\section{Conclusion}

A good removal of nitrate was observed by fixed-bed by PAN-oxime-nano $\mathrm{Fe}_{2} \mathrm{O}$. The adsorption studied showed that at longer bed depth better removal of nitrate would be achieved. The calculated adsorption capacity $\left(\mathrm{N}_{0}\right)$ and the rate constant $\left(\mathrm{K}_{\mathrm{a}}\right)$ were $1433 \mathrm{Mg} / \mathrm{L}$ and $0.0112 \mathrm{~L} / \mathrm{mg} \mathrm{h}$, respectively. Thomas and BDST models were successfully used for predicting breakthrough curves for nitrate removal using different flow rates and depth. The application of the BDST model at $10 \%$ of breakthrough point gave satisfactory results with an $R^{2}=0.999$.

\section{Competing interests}

The authors declare that they have no competing interests.

\section{Authors' contributions}

MJ, MR and RN participated in design of the column studies and performed experimental procedures. AJ and MJ participated in statistical analysis. MJ and MR drafted the manuscript. All authors read and approved the final manuscript.

\section{Acknowledgment}

The authors would like to thank the staff of medical sciences research center, Islamic Azad University, Tehran, Iran for their collaboration in this research.

\section{Author details}

'Department of Environmental Health Engineering, Islamic Azad University, Tehran Medical Sciences Branch, Tehran, Iran. ${ }^{2}$ Department of Environmental Health Engineering, School of public health, Yasuj University of Medical Sciences, Yasuj, Iran. ${ }^{3}$ Department of Environmental Health Engineering, Alborz University of Medical Sciences, Alborz, Iran. ${ }^{4}$ Center for Air Pollution Research, Institute of Environmental Research, Tehran University of Medical Sciences, Tehran, Iran.

Received: 18 January 2014 Accepted: 28 May 2014

Published: 4 June 2014

\section{References}

1. Nixon N: English water utility tackles nitrate removal. Water Eng Manage 1992, 139(3):27-28.

2. Bailey-Watts AE, Gunn IMD, Kirika A: 'Loch Leven: Past and Current Water Quality and Options for Change.' Edinburgh: Report to the Fourth River Purification Board, Institute of Freshwater Ecology; 1993.

3. Manahan Stanley E: Fundamentals of Environmental Chemistry. Boca Raton: CRC PressLLC; 2001.

4. Vladimir NB: Environmental Chemistry: Asian Lessons. New York, Boston, Dordrecht, London, Moscow: Kluwer Academic Publishers; 2003.

5. Huang $\mathrm{YH}$, Zhang TC: Effects of low $\mathrm{pH}$ on nitrate reduction by iron powder. Water Res 2004, 38:2631-2642.

6. Schoeman JJ, Steyn A: Nitrate removal with reverse osmosis in a rural area in South Africa. Desalination 2003, 155:15-26.

7. Hell F, Lahnsteiner J, Frischherz H, Baumgartner G: Experience with full-scale electrodialysis for nitrate and hardness removal. Desalination 1998, 117:173-180.

8. Samatya S, Kabay N, Yuksel U, Arda M, Yuksel M: Removal of nitrate from aqueous solution by nitrate selective ion exchange resins. Reac Funct Polym 2006, 66:1206-1214.

9. Baba Y, Ohguma K, Kawano K: Highly selective adsorption resins, Synthesis of chitosan derivatives and their adsorption properties for nitrate anion. Chem 1999, J1999(7):471-472.

10. Bao ML, Griffini O, Santianni D, Barbieri K, Burrini Dand Pantani F: Removal of bromate ion from water using granular activated carbon. Water Res 1999 33:2959-2970.

11. Nabizadeh R, Jahangiri-Rad M, Yunesian M, Nouri J, Moattar F, Sadjadi F: Synthesis and characterization of functionalized polyacrylonitrile coated with iron oxide nanoparticles and its applicability in nitrate removal from aqueous Solution. Des awter treatment 2013, doi:10.1080/ 19443994.2013.867816.

12. Gupta VK: Equilibrium uptake, sorption dynamics, process development, and column operations for the removal of copper and nickel fromaqueous solution andwastewater using activated slag, a low-cost adsorbent. Ind Eng Chem Res 1998, 37:192-202.

13. Baek K, Song S, Kang S, Rhee Y, Lee C, Lee B, Hudson S, Hwang T: Adsorption kinetics of boron by anion exchange resin in packed column bed. J Ind Eng Chem 2007, 13(3):452-456.

14. Chang H, Yuan X, Tian H, Zeng A-W: Experiment and prediction of breakthrough curves for packed bed adsorption of water vapor on cornmeal. Chem Eng Process 2006, 45:747-754.

15. Goud W, Mohanty K, Rao MS, Jayakumar NS: Prediction of mass transfer coefficients in packed bed using tamarind nut shell activated carbon to remove phenol. Chem Eng Technol 2005, 28(9):991-997.

16. Khraisheh MA, Al-Degs YS, Allen S, Ahmad M: Elucidation of the controlling steps of reactive dyes adsorption on activated carbon. Ind Eng Chem Res 2002, 41:1651-1657.

17. Faust SD, Aly OM: Adsorption Processes for Water Treatment. Guidford, Butterworth Scientific Ltd: Butterworth Publishers; 1987. ISBN 0-409-90000-1.

18. Kavak $D$, Öztürk N: Adsorption of boron from aqueous solution by sepirolite: II Column studies. II Illusirararasi Bor Sempozyumu 2004, 23-25:495-500.

\section{doi:10.1186/2052-336X-12-90}

Cite this article as: Jahangiri-rad et al:: Adsorption performance of packed bed column for nitrate removal using PAN-oxime-nano $\mathrm{Fe}_{2} \mathrm{O}_{3}$. Journal of Environmental Health Science \& Engineering 2014 12:90. 